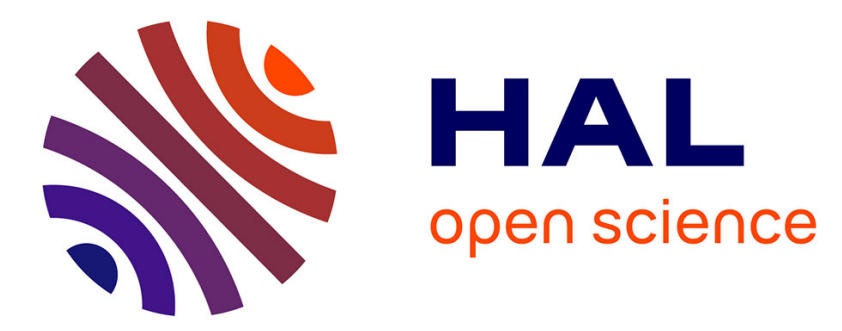

\title{
Optimization of Multi-part 3D Printing Build Strategies for Lean Product and Process Development
}

\author{
Nicola Garzaniti, Alessandro Golkar, Clément Fortin
}

\section{To cite this version:}

Nicola Garzaniti, Alessandro Golkar, Clément Fortin. Optimization of Multi-part 3D Printing Build Strategies for Lean Product and Process Development. 15th IFIP International Conference on Product Lifecycle Management (PLM), Jul 2018, Turin, Italy. pp.488-497, 10.1007/978-3-030-01614-2_45 . hal-02075554

\section{HAL Id: hal-02075554 https://hal.inria.fr/hal-02075554}

Submitted on 21 Mar 2019

HAL is a multi-disciplinary open access archive for the deposit and dissemination of scientific research documents, whether they are published or not. The documents may come from teaching and research institutions in France or abroad, or from public or private research centers.
L'archive ouverte pluridisciplinaire HAL, est destinée au dépôt et à la diffusion de documents scientifiques de niveau recherche, publiés ou non, émanant des établissements d'enseignement et de recherche français ou étrangers, des laboratoires publics ou privés. 


\title{
Optimization of multi-part 3D printing build strategies for lean product and process development
}

\author{
Nicola Garzaniti ${ }^{1 *}$, Alessandro Golkar ${ }^{1}$, Clément Fortin ${ }^{1}$ \\ ${ }^{1}$ Skolkovo Institute of Science and Technology, Space Center, \\ Nobel Street 3, 464 Skolkovo, Moscow 143026, Russia \\ *nicola.garzanitieskoltech.ru
}

\begin{abstract}
In recent years, the engineering community realized the potential of additive manufacturing (AM) technology to be a game changer in product development and manufacturing. The capability of AM to build tailored products within short lead-time can make it a key contributor to Industry 4.0 in a lean manufacturing perspective

This paper aims to assess how additive manufacturing can enable the implementation of lean product and process development practices, within a Product Lifecyle Management (PLM) perspective. We propose the use and the implementation of Design of Experiments (DoE) in a PLM tool to evaluate how part orientation, nesting and support strategy affects the total costs and time for product development and manufacturing. Then, we use the results of DoE analysis to optimize the multi-part 3D printing build strategies, to reduce waste of raw material and increase the overall quality of the final component.

Finally, we foresee the integration of this work in a wider multidisciplinary approach to comprehensively evaluate the use the of AM in the design of systems as early as at the conceptual design phase.

In this paper we present one of the case studies experimentally tested and validated.
\end{abstract}

Keywords: Additive manufacturing, Lean manufacturing, cost-effectiveness analysis, PLM

\section{Introduction}

Over the last decade, manufacturing companies are facing significant challenges concerning the disruptive concept of Industry 4.0 [1]. It refers to a wide range of ideas, which cover several aspects related to product development and manufacturing [2].

In this context, Additive Manufacturing (AM) technologies drew significant interest from both academia and industry [3]. The engineering community realized the potential of AM to be a game changer in product development [4-6]. The capability of AM to build tailored products within short lead-time can make it a key contributor to Industry 4.0 in a lean manufacturing perspective [7].

adfa, p. 1, 2011.

(C) Springer-Verlag Berlin Heidelberg 2011 
The lean philosophy aims at minimizing waste within a manufacturing process. Originally, it was focused on eliminating rework, unnecessary processing steps, waiting time, excess inventory and overproduction. Nowadays, it covers all the aspects of product development starting from the early stage of product life cycle, such as conceptual design, over to the manufacturing and distribution [8].

To enable the implementation of lean practices in product development and manufacturing, we focus on AM technology and analyze how to implement lean practices in the manufacturing process. Currently, market offers several PLM solutions to support 3D printing (i.e. solid and surface modeling, geometry meshing, STL slicing, Gcode generation or its equivalent); however, most of them do not provide comprehensive information aimed to optimize multipart build strategies within a given volume.

Therefore, a lack of fundamental design guidelines of lean manufacturing practices suitable for AM can be observed. These guidelines, once well-defined can be implemented in a PLM optimization module that could be used early in the product lifecycle at the product development and the manufacturing stages. They could thus lean the product and process development for AM.

This paper investigates this concern by addressing two research questions:

1. Which design variables affect mostly the cost-effectiveness of AM processes?

2. How can we define a set of optimal levels of these parameters to enhance the costeffectiveness of the process?

We limit our scope to Powder Bed Fusion (PBF) [9] for metals, which is the AM technologies that has been identified as the most industrially relevant at the time of writing of this paper.

The remainder of the paper is structured as follows. Section 2 illustrates the proposed approach. Section 3 discusses the results. Section 4 draws conclusions from the research and identifies avenues of future work.

\section{Approach}

We propose the use and the implementation of Design of Experiments (DoE) in a multidisciplinary PLM tool to identify lean practices in additive manufacturing (AM). The DoE method [10] consists of a set of statistical techniques, that provide a systematic way to sample the design space and to study the effects of the input variables on the output parameters.

Considering the overall steps to move from virtual CAD description to physical artifact development (Fig. 1), the approach we prose focuses on data preparation. It analyzes how the design variables involved in the building processes affect time and cost. The output of DoE is useful for identifying an optimal set-up [11] to reduce waste, particularly time and cost, in building parts using AM. 


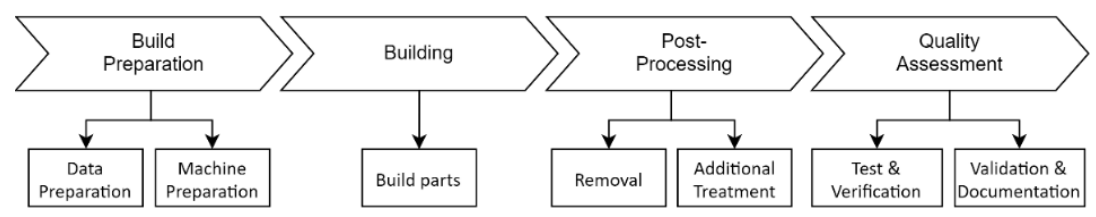

Fig. 1. AM Overall workflow [12]

The first step consists in identifying the parameters we want to investigate, called factors, and defining appropriate design variable ranges, called levels. In the second step we select the most appropriate DoE techniques. Then, we delineate the Matrix of Experiments, where each row corresponds to one observation. Finally, we evaluate cost and time for each combination of variables stated in the matrix.

In data preparation phase, engineers have to select the nesting, part orientation and to define the support strategy. Therefore, we identified five factors which can influence cost and time needed to build parts using AM. In Table 1 we list them while providing a brief description.

Table 1. Factors

\begin{tabular}{ll}
\hline \hline Factors & Description \\
\hline Nesting & $\begin{array}{l}\text { Process of laying out parts on the building plate to } \\
\text { maximize the chamber filling and minimize the raw } \\
\text { material waste } \\
\text { Height along z direction of the component we want to } \\
\text { build using AM } \\
\text { Volume of supports that have to provide a robust at- } \\
\text { tachment to the build plane } \\
\text { Solid supports volume }\end{array}$ \\
Solid supports surface area \\
Wafer supports surface area \\
$\begin{array}{l}\text { ment to the build plane } \\
\text { Area of a non-solid supports which are used to dissi- } \\
\text { pate the heat }\end{array}$ \\
\hline \hline
\end{tabular}

The definition of those factors has been mainly driven by the scan strategy associated to the generic PBF process. In this technology, each feature is built layer by layer, starting from the contour subsequently filled with a raster scan. Therefore, considering all the layers, contours become surfaces and filled areas become volumes. Literature provides many other parameters, which could be considered [13]. Nevertheless, most of them have a higher influence on the mechanical properties rather than cost [14], therefore, as a first approximation, they have not been considered in this discussion. However, they could be included into future improvements of this approach.

For each factor, a proper number of levels needs to be defined. The level of granularity must be sufficient to characterize the problem, without unacceptably penalizing computational cost. 
Concerning nesting, we consider the parts' bounding box, therefore, we define $l$ levels corresponding to the maximum number of components we can allocate to fill the chamber. Concerning the height along the z-direction, we define $l$ levels included between the minimum size of parts' bounding box, corresponding to one of its side, and the maximum one, that corresponds to the internal diagonal. Therefore, depending on the orientation selected, it may happen that z-height is greater than the nominal bounding box dimensions.

With regards to the support strategy, we decided to define the levels as a percentage of the volume or area of the components in question. A minimum value of $5 \%$ to a maximum of $30 \%$ has been considered.

In the second step, we need to select the DoE techniques and delineate the Matrix of Experiments. The full factorial design is the best choice if it is computationally feasible. If a complete investigation is too expensive, the use of the one or two-factor technique can be considered.

Subsequently, we evaluate cost and time for each experiment stated in the matrix. To perform this task, we used the AM evaluation tool developed by the authors [12]. It consists of a manufacturing cost model, based on actual process flows foreseen for powder-based process. As input, the user has to provide information about the part to manufacture. As output, the tool presents a detailed cost and time breakdown structure. The model is based on two general equations, one for the recurring cost (RC) and one for non-recurring cost (NRC). The total cost is the sum of each of them.

$$
\begin{cases}R C_{i}=\sum_{j}\left(h r_{i_{j}} \cdot t_{i_{j}}\right) & \text { if phase } \neq \text { building part } \\ R C_{i}=r m_{c} \cdot m_{p}+e_{c} \cdot e_{p} \cdot t_{i} & \text { if phase }=\text { building part }\end{cases}
$$

Where:

$R C_{i} \quad$ - Recurring cost concerned with ith manufacturing phase (€)

$h r_{i_{j}} \quad$ - Hourly rate of the jth task concerned with ith manufacturing phase $(€ / \mathrm{h})$

$t_{i_{j}} \quad$ - Time concerned with $j t h$ task of the ith manufacturing phase (h)

$r m_{c} \quad-$ Raw material cost $(€ / \mathrm{kg})$

$m_{p} \quad$ - Total mass of the building job (parts and waste material) $(\mathrm{kg})$

$e_{c} \quad$ - Energy consumption $(\mathrm{kW} / \mathrm{h})$

$t_{i} \quad$ - Time concerned with ith manufacturing phase (h)

$e_{p} \quad-$ Energy price $(€ / \mathrm{kW})$

$$
N R C_{i}=\frac{\text { CapEx }}{d_{t} \cdot u_{t}} \cdot t_{i}+\frac{O p E x}{u_{t}} \cdot t_{i}+N R C_{p v_{i}}
$$

$N R C_{i} \quad$ - Non- recurring cost concerned with ith manufacturing phase $(€)$

CapEx - Capital Expenditure $(€)$

$O p E x$ - Operating Expenditure $(€ / y)$

$d_{t} \quad$ - Depreciation time $(\mathrm{y})$

$u_{t} \quad$ - Machine usage $(\mathrm{h} / \mathrm{y})$

$t_{i} \quad$ - Time concerned with ith manufacturing phase (h)

$N R C_{p v_{i}}$ - NRC, concerned with ith manufacturing phase, amortised on a specific part type, therefore affected by production volume (e.g. data preparation) $(€)$ 
Then, we used the results to calculate the main effect of a factor. It is the effect of a factor on the output averaged across the levels of other factors.

The output of DoE analysis exhibits the relationship between the different variables. It offers information useful to identify factors that mostly affect the costs and time of building parts using AM. The results are therefore used to optimize the AM process to reduce waste in a lean perspective.

\section{Results}

In this paragraph, our approach applied to a concrete case study is presented. We considered the hydraulic manifold of an aircraft. Its function is to regulate fluid flow between pumps and actuators in a hydraulic system. It lets the operator control how much fluid flows between components of the system, therefore controlling the behavior of actuators. This component has been identified as one of the most suitable to be manufactured using AM.

We adopt a simulation driven design approach [15] (i.e. to use PLM methods and tools to support design decisions) to move from a preliminary design to a topology optimized design [16]. Fig. 2 shows the overall workflow foreseen to achieve the design which benefits most from the great geometry freedom enabled by additive techniques. We start selecting the component to be optimized: a hydraulic manifold made of Ti-6Al-4V (Fig. 2-1, green element). Then we define the design domain, the overall loads, and the preliminary properties and constraints of the part (Fig. 2-2, purple areas). Subsequently, we run the optimization code (Fig. 2-3) and finalize the design (Fig. 2-4).

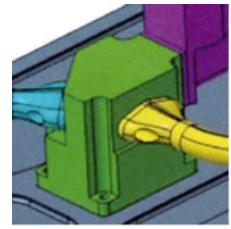

(1)

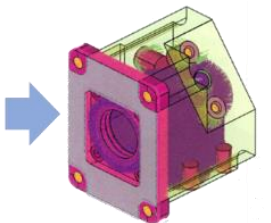

(2)

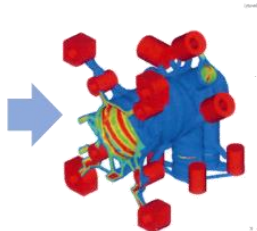

(3)

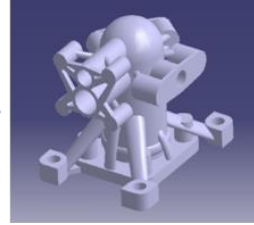

(4)

Fig. 2. Workflow to move from a preliminary to a topology optimized design

In Table 2 we summarize the geometrical characteristics of the manifold selected (size of bounding box, effective volume and area) needed for the subsequent analysis.

Table 2. Hydraulic manifold geometrical characteristics

\begin{tabular}{lll}
\hline \hline Item & Value & metric \\
\hline Length & 75 & $\mathrm{~mm}$ \\
Width & 75 & $\mathrm{~mm}$ \\
Height & 85 & $\mathrm{~mm}$ \\
Volume & 76178 & $\mathrm{~mm}^{3}$ \\
Surface area & 43000 & $\mathrm{~mm}^{2}$ \\
\hline \hline
\end{tabular}


In order to set up properly the DoE, the definition of the machine model, thus the build volume is required. A SLM 3D printer for metal, with a build volume of $250 \times 250 \times 315 \mathrm{~mm}$, has been considered.

The second step is to define an appropriate number of levels, then select a proper DoE technique and delineate the matrix of experiments.

Considering the component size and the machine characteristics, we decided to define six level for each factor. We set a nesting value from one up to six. Concerning the height along the $\mathrm{z}$-direction, we set equispaced value from $75 \mathrm{~mm}$ to $136 \mathrm{~mm}$. As regards the support strategy, we define equispaced levels in the range from $5 \%$ to $30 \%$ of part's volume or area.

Table 3. Factors and levels

\begin{tabular}{lllllll}
\hline \hline Factor & \multicolumn{7}{c}{ Levels } & & & & \\
\hline Nesting & 1 & 2 & 3 & 4 & 5 & 6 \\
Z-height (mm) & 75 & 87.2 & 99.4 & 111.6 & 123.8 & 136 \\
Solid s. volume & $5 \%$ & $10 \%$ & $15 \%$ & $20 \%$ & $25 \%$ & $30 \%$ \\
Solid s. surface area & $5 \%$ & $10 \%$ & $15 \%$ & $20 \%$ & $25 \%$ & $30 \%$ \\
Wafer s. surface area & $5 \%$ & $10 \%$ & $15 \%$ & $20 \%$ & $25 \%$ & $30 \%$ \\
\hline \hline
\end{tabular}

If we want to perform a full factorial design, 7776 observations are needed. This investigation is complete but too expensive.

$$
l^{n}=7776 \text { observations }
$$

Where:

$-n$ is the number of factors

$-l$ is the number of levels.

Considering the use of one-factor method, we have to perform 26 observations.

$$
1+n(l-1)=26 \text { observations }
$$

Therefore, we decided to use the one-factor method and built the corresponding matrix. Subsequently, we evaluated cost. In Table 4 the matrix of experiments and related cost and time is exhibited.

Table 4. Matrix of experiments, cost and time

\begin{tabular}{cccccccc}
\hline \hline Exp N. & nesting & $\begin{array}{c}\text { z-height } \\
(\mathbf{m m})\end{array}$ & $\begin{array}{c}\text { Solid s } \\
\text { volume }\end{array}$ & $\begin{array}{c}\text { Solid s } \\
\text { S area }\end{array}$ & $\begin{array}{c}\text { Wafer s } \\
\text { S Area }\end{array}$ & $\begin{array}{c}\text { Cost } \\
\boldsymbol{\epsilon}\end{array}$ & $\begin{array}{c}\text { Time } \\
\text { h }\end{array}$ \\
\hline 1 & 1 & 75 & $5 \%$ & 1 & $5 \%$ & 2815 & 25 \\
2 & 2 & 75 & $5 \%$ & $5 \%$ & $5 \%$ & 1553 & 16 \\
3 & 3 & 75 & $5 \%$ & $5 \%$ & $5 \%$ & 1133 & 13 \\
4 & 4 & 75 & $5 \%$ & $5 \%$ & $5 \%$ & 922 & 12 \\
5 & 5 & 75 & $5 \%$ & $5 \%$ & $5 \%$ & 796 & 11 \\
6 & 6 & 75 & $5 \%$ & $5 \%$ & $5 \%$ & 712 & 10 \\
7 & 6 & 87.2 & $5 \%$ & $5 \%$ & $5 \%$ & 757 & 10 \\
\hline \hline
\end{tabular}




\begin{tabular}{cccccccc}
\hline \hline 8 & 6 & 99.4 & $5 \%$ & $5 \%$ & $5 \%$ & 803 & 10 \\
9 & 6 & 111.6 & $5 \%$ & $5 \%$ & $5 \%$ & 848 & 11 \\
10 & 6 & 123.8 & $5 \%$ & $5 \%$ & $5 \%$ & 893 & 11 \\
11 & 6 & 136 & $5 \%$ & $5 \%$ & $5 \%$ & 939 & 11 \\
12 & 6 & 75 & $10 \%$ & $5 \%$ & $5 \%$ & 719 & 10 \\
13 & 6 & 75 & $15 \%$ & $5 \%$ & $5 \%$ & 726 & 10 \\
14 & 6 & 75 & $20 \%$ & $5 \%$ & $5 \%$ & 733 & 11 \\
15 & 6 & 75 & $25 \%$ & $5 \%$ & $5 \%$ & 740 & 11 \\
16 & 6 & 75 & $30 \%$ & $5 \%$ & $5 \%$ & 747 & 11 \\
17 & 6 & 75 & $5 \%$ & $10 \%$ & $5 \%$ & 713 & 10 \\
18 & 6 & 75 & $5 \%$ & $15 \%$ & $5 \%$ & 714 & 10 \\
19 & 6 & 75 & $5 \%$ & $20 \%$ & $5 \%$ & 714 & 10 \\
20 & 6 & 75 & $5 \%$ & $25 \%$ & $5 \%$ & 715 & 10 \\
21 & 6 & 75 & $5 \%$ & $30 \%$ & $5 \%$ & 716 & 10 \\
22 & 6 & 75 & $5 \%$ & $5 \%$ & $10 \%$ & 713 & 10 \\
23 & 6 & 75 & $5 \%$ & $5 \%$ & $15 \%$ & 715 & 10 \\
24 & 6 & 75 & $5 \%$ & $5 \%$ & $20 \%$ & 716 & 10 \\
25 & 6 & 75 & $5 \%$ & $5 \%$ & $25 \%$ & 718 & 10 \\
\hline \hline
\end{tabular}

We use the data in Table 4 to calculate the effect of factors. The analysis highlighted that nesting and $\mathrm{z}$-height have a higher impact on cost and time than other factors. The first one has a coefficient of variation, also known as relative standard deviation, of 0.55 and the second of 0.09 , the others lower than 0.01 .

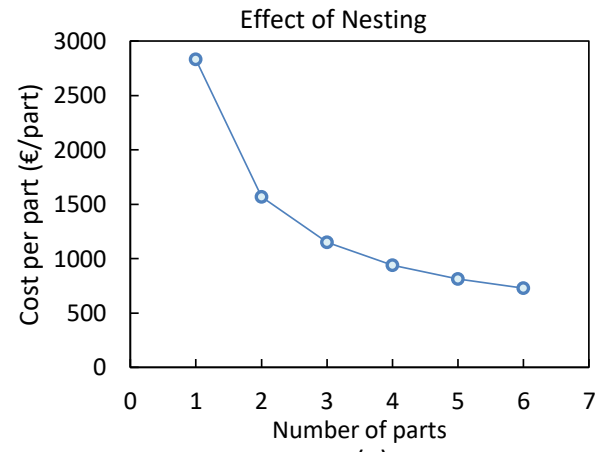

(a)

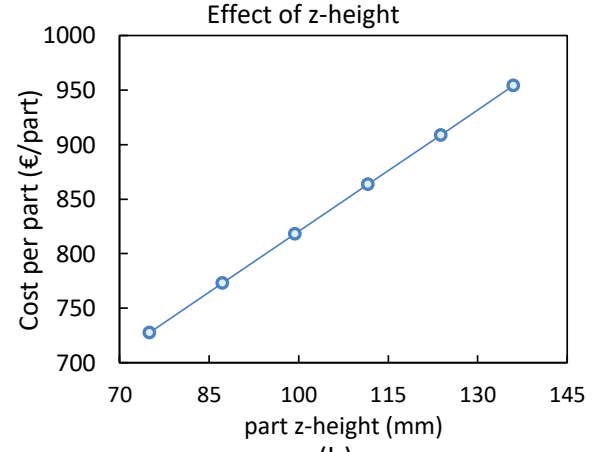

(b)

Fig. 3. Effect of nesting (a) and height along $\mathrm{z}$ on cost (b)

The results of DoE analysis offer preliminary information aimed at selecting a set of optimal parameters to reduce waste in manufacturing parts using AM.

The cost-effectiveness of the process is greatly influenced by the volumetric packing density of the part within the build chamber. Therefore, it is highly recommended to define a part orientation that most efficiently enables other parts (similar or different in geometry) to fit around it. In some circumstances, parts may also be clustered into groups and supported from one another. 
The cost and time are directly proportional to the maximum height of components along the $\mathrm{z}$-direction. The expenses grow with the increase of height due to the increment of the number of layers. It is therefore preferable to minimize the size along the z-axis.

Orientation of components in the chamber also has significant effect on the buildup quality, because parts' properties change according to layer direction. It influences the surface finish (roughness), the part strength in a specific direction, the geometric accuracy and the part stability in the building process. Therefore, all those issues should also be taken into account within the data preparation practice.

As in most engineering problems, criteria to minimize cost and time while ensuring appropriate quality of the product can conflict. So, the objective is to identify and select the best compromise solution for the scenario being considered.

All the results presented here were obtained by the implementation of DoE analysis in a PLM tool, tailored for AM process. It performs the analysis and it provides the data summarized in Table 4 and Fig. 3 as output.

Furthermore, considering the two factors with the highest effect, the tool evaluates cost (or time) for different combination of those factors, while increasing number of levels. The infeasible solutions (i.e. max building chamber's dimensions exceeded) are automatically excluded from the analysis.

This is useful to identify the solution that minimize cost and time, constrained to the production volume foreseen/required. Fig. 4 shows that in case of one-off component it is possible to minimize z-height (blue dots), meanwhile increasing the production volume it is not possible to reduce under a given threshold (green marks).

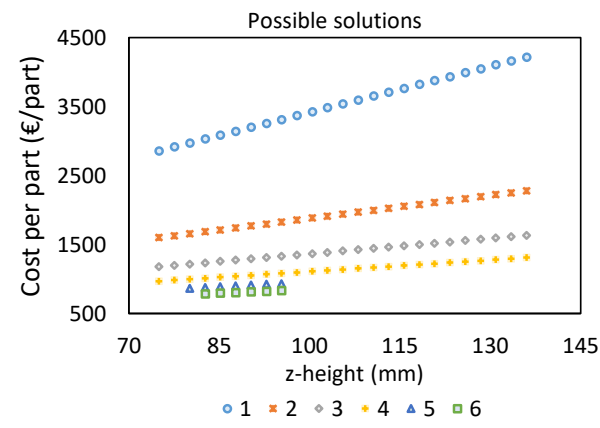

(a)

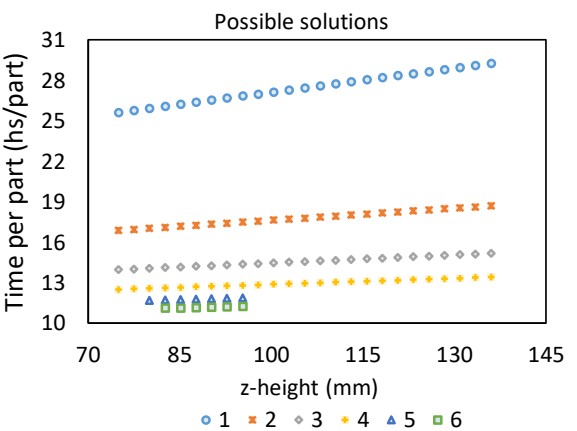

(b)

Fig. 4. Optimization (a) cost - (b) time

The research work presented here has been experimentally tested and validated on different builds, including multiple geometries and different quantities. In this paper we presented one of the case studies analyzed.

The tests have been performed in the Additive Manufacturing Laboratory of a European aerospace company. The laboratory also provided the facilities and tools to manufacture the components involved in the analysis.

The estimations and the experimental data are in very good agreement: we have a level of uncertainty lower than $5 \%$ for the manufacturing cost and time. This proves the validity of the proposed guidelines that can be implemented in a PLM system. 


\section{Conclusions}

Deployment of AM technologies represents a highly effective way to enable the implementation of lean philosophy within Industry 4.0. The main objective of this paper was to propose a methodology to identify lean practices in additive manufacturing and implement it in a PLM tool. Here we briefly summarize main findings of the research highlighting potential and limitation of our approach.

We introduced the use of DoE to identify the design variables which most affect the cost-effectiveness of AM process. Then we used the results to define a set of optimal parameters to reduce waste in manufacturing using AM.

The research investigates the relationship between orientation, support strategy, nesting and cost/time, and provides a systematic approach to perform quantitative analysis of the cost-benefit for AM process. Furthermore, we present some preliminary results to be used for optimization of design variables to reduce raw material waste and shorten lead time.

The analysis highlighted that z-height and nesting have a higher impact on cost and time than other variables. Therefore, we can identify and select the best compromise solution for the scenario being considered, in order to minimize cost and time while ensuring appropriate quality.

The work presented here has to be considered in a wider perspective and it opens the potential for several other topics to be investigated. It shall be integrated in a multidisciplinary PLM tool aimed to comprehensively evaluate the use the of AM in the design of systems already. This wider approach would provide information on how to support the prototyping and manufacturing technique decision-making process.

Several research works have been dedicated to the different AM core topics making this technology to be key contributor to the Industry 4.0. However, we also need improvements in systems engineering practices and PLM approaches to make it more competitive on the global market. This work intended to contribute to this future and this vision shaping a strategy to enable the deployment of lean practices within AM technologies.

\section{Acknowledgments}

The authors would like to thank Mr. Jonathan Meyer form Airbus for his valuable contribution, and for giving access to the data used to test and validate the tool.

\section{References}

[1] A. Schumacher, S. Erol, W. Sihn, A maturity model for assessing Industry 4.0 readiness and maturity of manufacturing enterprises, Procedia CIRP. 52 (2016) 161-166. doi:10.1016/j.procir.2016.07.040.

[2] H. Lasi, P. Fettke, H.G. Kemper, T. Feld, M. Hoffmann, Industry 4.0, Business and Information Systems Engineering. 6 (2014) 239-242. 
doi:10.1007/s12599-014-0334-4.

[3] W. Gao, Y. Zhang, D. Ramanujan, K. Ramani, Y. Chen, C.B. Williams, C.C.L. Wang, Y.C. Shin, S. Zhang, P.D. Zavattieri, The status, challenges, and future of additive manufacturing in engineering, Computer-Aided Design. 69 (2015) 65-89. doi:10.1016/j.cad.2015.04.001.

[4] I. Wohlers Associates, Wohlers report 2017: 3D printing and additive manufacturing state of the industry : annual worldwide progress report., 2017. https://wohlersassociates.com/2017contents.htm.

[5] S. Yang, Y.F. Zhao, Additive manufacturing-enabled design theory and methodology: a critical review, International Journal of Advanced Manufacturing Technology. 80 (2015) 327-342. doi:10.1007/s00170-0156994-5.

[6] P.C. Priarone, G. Ingarao, Towards criteria for sustainable process selection: On the modelling of pure subtractive versus additive/subtractive integrated manufacturing approaches, Journal of Cleaner Production. 144 (2017) 57-68. doi:10.1016/j.jclepro.2016.12.165.

[7] C. Santos, A. Mehrsai, A.C. Barros, M. Araújo, E. Ares, Towards Industry 4.0: an overview of European strategic roadmaps, Procedia Manufacturing. 13 (2017) 972-979. doi:10.1016/j.promfg.2017.09.093.

[8] B. Mrugalska, M.K. Wyrwicka, Towards Lean Production in Industry 4.0, $\begin{array}{lllll}\text { Procedia } & \text { Engineering. } & 182 & \text { (2017) }\end{array}$ doi:10.1016/j.proeng.2017.03.135.

[9] ASTM F42.91, F2792-12a: Standard Terminology for Additive Manufacturing Technologies, ASTM International. West Consh (2012) 1-3. doi:10.1520/F2792-12A.

[10] M. Uy, J.K. Telford, Optimization by Design of Experiment techniques, in: 2009 IEEE Aerospace Conference, IEEE, 2009: pp. 1-10. doi:10.1109/AERO.2009.4839625.

[11] D.C. Montgomery, Design and analysis of experiments, John Wiley \& Sons, Inc, 2013.

[12] N. Garzaniti, Influences of additive manufacturing in concurrent engineering process for aerospace applications, Thesis, Department of Mechanical and Aerospace Engineering, Politecnico di Torino, 2017.

[13] S. Sun, M. Brandt, M. Easton, Powder bed fusion processes, in: Laser Additive Manufacturing, Elsevier, 2017: pp. 55-77. doi:10.1016/B978-0-08100433-3.00002-6.

[14] F. Calignano, G. Cattano, D. Manfredi, Manufacturing of thin wall structures in AlSi10Mg alloy by laser powder bed fusion through process parameters, Journal of Materials Processing Technology. 255 (2018) 773-783. doi:10.1016/j.jmatprotec.2018.01.029.

[15] U. Sellgren, Simulation-Driven Design - Motives, Means, and Opportunities, KTH, 1999.

[16] O. Sigmund, K. Maute, Topology optimization approaches, Structural and Multidisciplinary Optimization. 48 (2013) 1031-1055. doi:10.1007/s00158013-0978-6. 